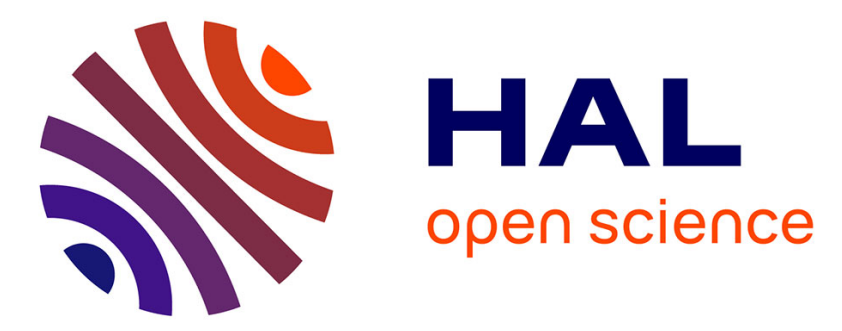

\title{
Growth, morphology and electronic properties of epitaxial graphene on vicinal $\operatorname{Ir}(332)$ surface
}

A Celis, M N Nair, M Sicot, F Nicolas, S Kubsky, A Taleb-Ibrahimi, D

Malterre, Antonio Tejeda

\section{- To cite this version:}

A Celis, M N Nair, M Sicot, F Nicolas, S Kubsky, et al.. Growth, morphology and electronic properties of epitaxial graphene on vicinal $\operatorname{Ir}(332)$ surface. Nanotechnology, 2020, 31 (28), pp.285601. 10.1088/1361-6528/ab866a . hal-03323068

\section{HAL Id: hal-03323068 \\ https://hal.science/hal-03323068}

Submitted on 20 Aug 2021

HAL is a multi-disciplinary open access archive for the deposit and dissemination of scientific research documents, whether they are published or not. The documents may come from teaching and research institutions in France or abroad, or from public or private research centers.
L'archive ouverte pluridisciplinaire HAL, est destinée au dépôt et à la diffusion de documents scientifiques de niveau recherche, publiés ou non, émanant des établissements d'enseignement et de recherche français ou étrangers, des laboratoires publics ou privés. 


\title{
Growth, morphology and electronic properties of epitaxial graphene on vicinal $\operatorname{Ir}(332)$ surface
}

\author{
A. Celis ${ }^{1}$, M. N. Nair, ${ }^{2,1,3}$ M. Sicot, ${ }^{4}$ F. Nicolas, ${ }^{2}$ S. Kubsky ${ }^{2}$, A. Taleb-Ibrahimi, ${ }^{2}$ D. Malterre, ${ }^{4}$ and A. \\ Tejeda $^{1,2}$
}

${ }^{1}$ Université Paris-Saclay, CNRS, Laboratoire de Physique des Solides, 91405, Orsay, France.

${ }^{2}$ Synchrotron SOLEIL/UR1 CNRS, Saint-Aubin, 91192, Gif-sur-Yvette, France

${ }^{3}$ CUNY Advanced Science Research Center, 85 St. Nicholas Terrace, New York, NY 10031, USA.

${ }^{4}$ Institut Jean Lamour, UMR 7198, CNRS-Université de Lorraine, Campus ARTEM, 2 Allée André Guinier, BP 50840, 54011 Nancy, France

E-mail: mnair@gc.cuny.edu

Received $\mathrm{xxxxxx}$

Accepted for publication $\mathrm{xxxxxx}$

Published xxxxxx

\begin{abstract}
Superlattice induced minigaps in graphene band structure due to underlying one-dimensional nanostructuration has been demonstrated. A superperiodic potential can be introduced in graphene if the substrate is periodically structured. The successful preparation of a periodically nanostructured substrate in large scale can be obtained by carefully studying the electronic structure with a spatial averaging technique such as high-energy resolution photoemission. In this work, we present two different growth methods such as temperature programmed growth (TPG) and chemical vapor deposition (CVD) studied by scanning tunnelling microscopy (STM) and low energy electron diffraction (LEED). In both methods, we show that the original steps of $\operatorname{Ir}(332)$ have modified with (111) terraces and step bunching after graphene growth. Graphene grows continuously over the terrace and the step bunching areas. We observe that while TPG growth does not give rise to a well-defined surface periodicity required for opening a bandgap, the CVD growth does. By combining with angle-resolved photoemission spectroscopy (ARPES) measurements, we correlate the obtained spatial periodicity to observed band gap opening in graphene.
\end{abstract}

Keywords: Graphene, photoelectron spectroscopy, growth, electronic properties, superperiodicity, bandgap

\section{Introduction}

The tailoring of graphene electronic properties is one of the major issues in this material, in particular the introduction of a sizeable bandgap. Different ways to open a bandgap have therefore been explored, as substrate-induced bandgap[1-5], nanostructuration[6-8], strain engineering[9], doping or functionalization of metal atoms or molecules[10-13]. A possible way to modify the band structure of graphene is applying a periodic potential. Periodicities on graphene can be generated by applying an electrostatic potential[14-18], magnetic barriers $[19,20]$, using periodically patterned gates, electron beam induced deposition of adatoms[21] or on graphene grown on metal surfaces[22-25]. When graphene grows on $\operatorname{Ir}(111)$ for instance, a superlattice appears due to the mismatch between the graphene and the substrate lattices which leads to moiré superstructures. These moirés add a long range superperiodic potential to graphene, which opens minigaps in the Dirac cone[24]. Theoretically, it has been shown that when a periodic potential is applied to graphene, some interesting properties can appear as Fermi velocity anisotropy[14,26,27], extra Dirac points[15][27], tunable bandgap at Dirac point [16] and a new class of massless Dirac fermions at $\mathrm{M}$ points in superlattice Brillouin zone boundaries (SBZ)[15].

Growth of graphene on vicinal substrates offers a much more flexible way to control the superperiodicity on graphene, 
since there are different available stable vicinal surfaces with different step width arrays. It is therefore possible to introduce a one-dimensional potential affecting the electronic properties of graphene[5,28-30]. Many of these studies have been conducted on silicon carbide substrates, where a honeycomb carbon layer can make covalent bonds to the substrate (usually called buffer layer) and thus a strong interaction to it. However, it has been observed that graphene grown on noble metal surfaces can also feel the effect of underlying periodicities. When graphene is grown on two different nanostructured vicinal metal surfaces, namely $\operatorname{Ir}(332)$ and $\operatorname{Pt}(111)$ vicinals, the electronic structure shows bandgap openings at the crossing of the initial Dirac cone with replicas arising from the superperiodicity[25]. A previous work of graphene grown on stepped $\operatorname{Ir}(332)$ has shown an anisotropic graphene $\pi$ bands due to the presence of a periodic potential originating from steps[31]. We develop here two different methods for growing graphene on vicinal $\operatorname{Ir}(332)$ substrate and correlate the growth conditions to the atomic morphology and the low energy electron diffraction (LEED) features. Finally, by combining with ARPES, we show how the different preparations can affect the quality of graphene and thus its electronic properties.

\section{Results and discussion}

\subsection{Structural Characterization}

We report here a growth procedure to synthesize epitaxial monolayer graphene on $\operatorname{Ir}(332)$ different from that reported earlier [32]. Here the synthesis takes place at high temperature and with different ethylene exposure. Earlier reports obtained Gr on $\operatorname{Ir}(332)$ with two different methods: (i) one TPG cycle followed by $\mathrm{CVD}$ at three different sample temparatures $770^{\circ} \mathrm{C}, 820^{\circ} \mathrm{C}$ and $930^{\circ} \mathrm{C}$ while keeping the ethylene pressure constant and (ii) $\mathrm{CVD}$ at $775^{\circ} \mathrm{C}$ and $880^{\circ} \mathrm{C}$. In our case, we study different ethylene exposure versus different temperatures until we obtain a well-ordered graphene layer. This will be discussed in detail in the following section.

Iridium substrates are known to have weak interaction with graphene. Therefore, it allows us to study the electronic properties of graphene in quasi-free-standing regime of high quality. (332) crystal plane because it pesents stable steps that can be used as a template for graphene growth and introducing a superperiodicity on graphene. We prepared our $\operatorname{Ir}(332)$ substrate by a series of sputtering and annealing cycles. The pristine $\operatorname{Ir}(332)$ surface consists of $\operatorname{Ir}(111)$ terraces of $1.2 \mathrm{~nm}$ that extend along the $[10 \overline{1}]$ direction and are periodic along the [121] direction (figure 1a). Figure 1b shows the STM topographic image of the clean $\operatorname{Ir}(332)$ surface with wellordered terraces. The LEED pattern of the clean $\operatorname{Ir}(332)$ surface is characterized by a well-defined Ir spots and no background intensity due to the carbon segregation during annealing or from residual atmosphere in UHV as shown in figure S1 in the supplementary information. The red dots show the (1x1) hexagonal periodicity of the Ir substrate and the blue dots show the splitting of these periodicities due to the periodic nature of the vicinal surface along [12 1$]$ the direction. Taking the distance between the $\operatorname{Ir}(1 \times 1)$ spots as a reference, the terrace size calculated by LEED is $1.8 \pm 0.2 \mathrm{~nm}$.
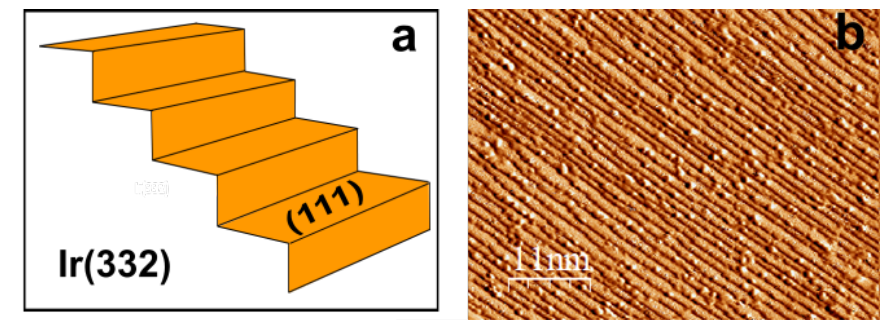

Figure 1. Clean $\operatorname{Ir}(332)$ substrate. (a) Scheme of stepped Ir(332) surface. (b) STM topography acquired on large area. Tunnelling voltage $\mathrm{V}_{\mathrm{T}}=1 \mathrm{~V}$, Tunnelling current $\mathrm{I}_{\mathrm{T}}=0.5 \mathrm{nA}$.

Graphene was then grown on top of this substrate by TPG. TPG on $\operatorname{Ir}(111)$ is known to originate separated graphene flakes[33-35], being thus promising for obtaining a network of disconnected nanoribbons instead of a continuous layer of graphene growing over the substrate steps. In order to obtain a network of graphene nanoribbons, we studied the growth of graphene through the diagram of annealing temperature versus the surface exposure of ethylene (figure 2a). We first determined the growth temperature of graphene on $\operatorname{Ir}(332)$ by performing one TPG cycle as a function of temperature until the graphene diffraction pattern appeared in LEED. We thus fixed that the appropriate temperature for graphene growth on $\operatorname{Ir}(332)$ above $800^{\circ} \mathrm{C}$, which is similar to that for graphene growth on $\operatorname{Ir}(111)$ [36]. Graphene is first seen at dosages around $7 \mathrm{~L}$. Later on, a series of consecutive TPG cycles above $800^{\circ} \mathrm{C}$ were performed in order to increase the graphene coverage.

Figure $2 \mathrm{~b}$ and $\mathrm{c}$ show the characterization of the initial graphene growth obtained after one TPG cycle at an effective dosage of 7L. In the process of graphene growth, the LEED spots associated to the initial step network disappear (figure 2b). i.e. LEED does not show the characteristic splitting of Ir spots that was observed for pristine $\operatorname{Ir}(332)$ surface (figure S1 in the supplementary information). A graphene spot with $0^{\circ}$ orientation (R0) surrounded by a moiré pattern was also observed. STM measurements allow to understand the growth process on this system. When graphene is grown, a stepbunching process takes place [32]. Steps coalesce leading to either partial or full step bunching (arrows in figure 2c) and the graphene patches appear on the wider (111) terraces, that can be easily recognised because of the different morphology compared to the $\operatorname{Ir}(332)$ surface, i.e. their corrugation is much 
less than the clean surface[36,37], as indicated by a dashed box in figure 2c. Step bunching has also been observed for graphene grown on other metal substrates such as flat $\operatorname{Ir}(111)$ terraces[36], $\mathrm{Ru}(0001)$ [38] and also on $\mathrm{SiC}$ substrate[39].
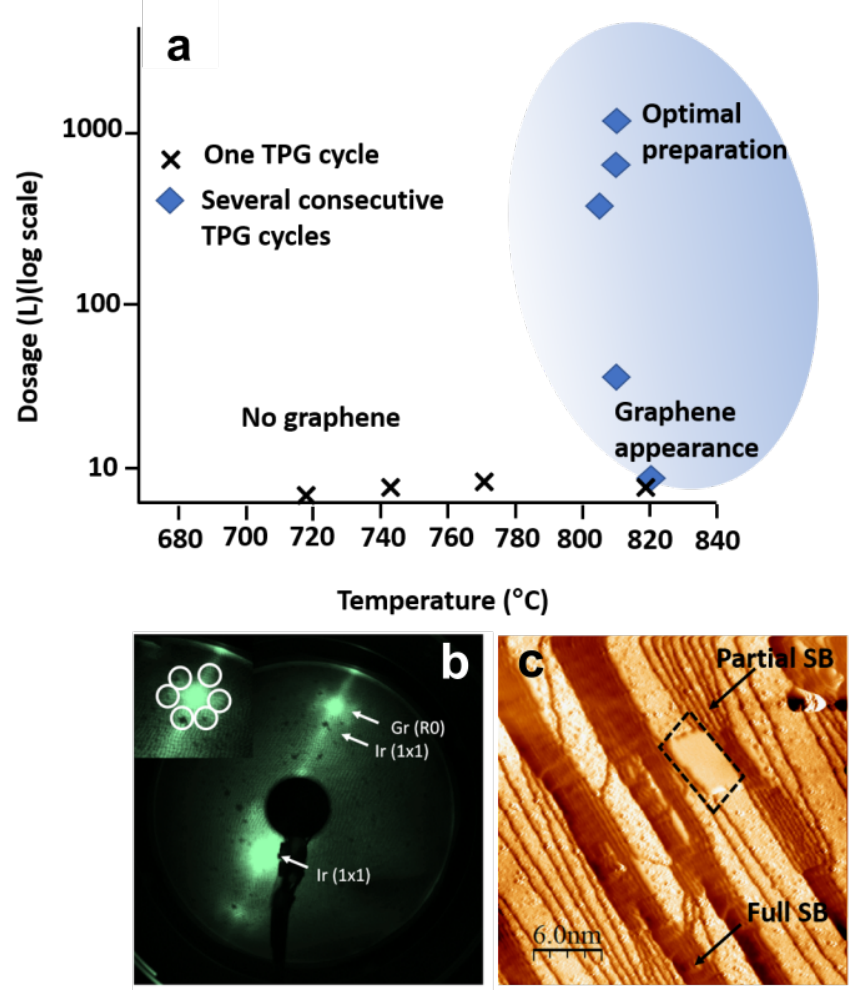

Figure 2. (a) Dosage vs. substrate annealing temperature for different TPG preparations. Crosses correspond to one TPG cycle preparations while blue diamonds correspond to several consecutive TPG cycles on the surface. The shaded region shows the boundary of graphene formation (b) and (c) show the LEED and STM image of initial stage of graphene growth obtained at an effective dosage of 7L. (b) LEED pattern (at $34 \mathrm{eV}$ ) shows the first order Ir spots, Gr spots as well as surrounding moiré (inset). (c) STM topograph exhibiting the step bunching (SB) and graphene formation (black dashed box) on the $\operatorname{Ir}(111)$ terraces. Tunnelling conditions $\mathrm{V}_{\mathrm{T}}=1 \mathrm{~V}$, $\mathrm{I}_{\mathrm{T}}=1 . \ln \mathrm{n}$.

When more TPG cycles are performed on the same surface, the graphene coverage increases due to the carbon accumulated on the surface, as seen in figure 3. Figure 3 shows the STM topographic images of graphene covered areas with different ethylene exposures. When increasing the effective dosage of ethylene, the surface is progressively covered as seen in figures $3 \mathrm{a}, 3 \mathrm{~b}, 3 \mathrm{c}$ and $3 \mathrm{~d}$. The LEED intensity does not change as the coverage is increased, so the quantification of the coverage is obtained from large scale STM images. Apart from graphene coverage, we have also observed an increase of round carbide islands [32].
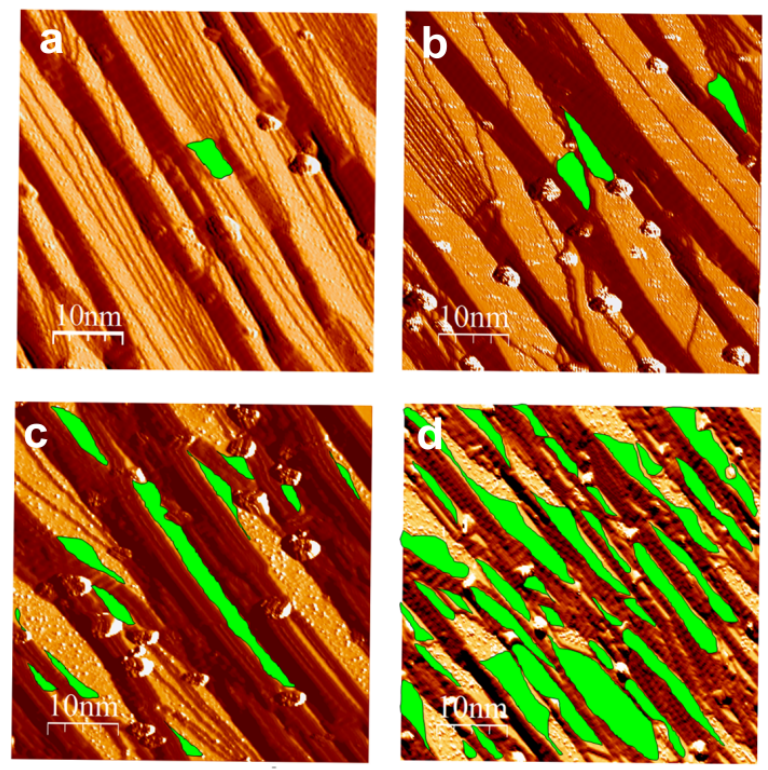

Figure 3. STM topographic images of graphene covered areas with different dosages of exylene exposure and several TPG cycles. (a) an effective dosage of $20 \mathrm{~L}$ with one TPG cycle, $\mathrm{V}_{\mathrm{T}}$ $=1 \mathrm{~V}, \mathrm{I}_{\mathrm{T}}=0.5 \mathrm{nA}$ (b) $200 \mathrm{~L}, \mathrm{~V}_{\mathrm{T}}=1 \mathrm{~V}, \mathrm{I}_{\mathrm{T}}=0.6 \mathrm{nA}$ (c) $700 \mathrm{~L}, \mathrm{~V}_{\mathrm{T}}$ $=1 \mathrm{~V}, \mathrm{I}_{\mathrm{T}}=0.6 \mathrm{nA}$ (d) $1000 \mathrm{~L}, \mathrm{~V}_{\mathrm{T}}=1 \mathrm{~V}, \mathrm{I}_{\mathrm{T}}=0.5 \mathrm{nA}$. (b), (c) and (d) performed respective dosages with several TPG cycles. Green colour represents graphene covered areas.

Figure 4 depicts our preparation when graphene was covering most of the Ir (332) substrate. The STM shows that the initial $\operatorname{Ir}(332)$ with a step network is now replaced by an arrangement of (111) terraces and step bunching areas. Graphene growing on the (111) terraces is shown in figure 4 , where panel a shows the original data and panel $b$ highlights the regions where graphene appears. The inset shows the atomic resolution of the pure monolayer graphene network which is rotated $0^{\circ}$ with respect to Ir. Graphene also grows in the step bunching areas, were a moiré pattern is visible. A continuous growth of graphene on terrace and step bunching is shown in figure S2a and S2b shows its corresponding height profile in the 
supplementary information. The STM shows the difficulty of obtaining a high periodic system when graphene is grown, so we have oriented ourselves to the CVD method.
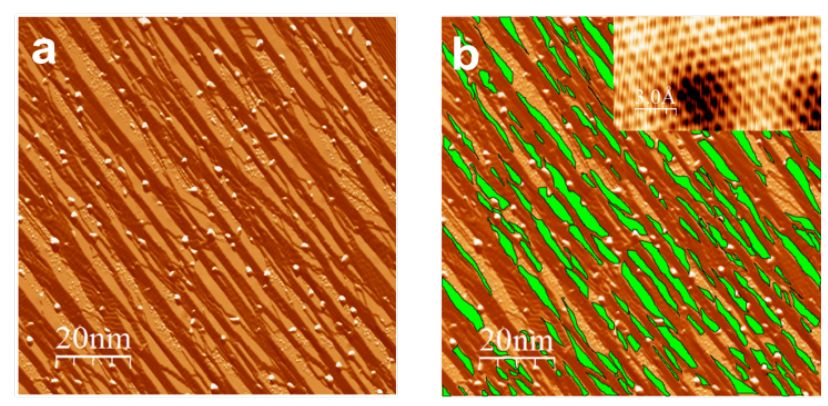

Figure 4. STM image of our best preparation. (a) STM image showing the Gr/Ir(332) sample obtained after three TPG cycles with an effective dosage of $1014 \pm 1$ L. Tunnelling Conditions $\mathrm{V}_{\mathrm{T}}=1 \mathrm{~V}, \mathrm{I}_{\mathrm{T}}=0.6 \mathrm{nA}$. (b) Green areas represent the graphene areas in (a). These areas do not extend across the whole length of the terrace. The inset of figure $b$ shows the graphene honeycomb network and a moiré pattern.

In CVD preparations, the growth was completely different, because a structural superperiodicity appears despite graphene growth. Fig. 5a shows the different dosage versus the annealing temperature that we explored until we reached our optimal preparation. We initially started with half of the dosage for covering a $\operatorname{Ir}(111)$ surface and $150^{\circ} \mathrm{C}$ below the typical temperature[40], i.e. $660^{\circ} \mathrm{C}$ and $22.5 \mathrm{~L}$. The LEED pattern of this preparation (fig. 5b) shows the characteristic (1x1) Ir spots and a diffuse background, but no traces of graphene. The origin of the diffuse intensity prior to graphene formation is the presence of disordered ethylene molecules that have not given rise to graphene yet. At a higher temperature $\left(715^{\circ} \mathrm{C}\right)$, that favours molecular dissociation and hence the graphene formation, and at a dosage of $34 \mathrm{~L}$, some structure is appreciated in the LEED pattern around the $(1 \mathrm{x} 1)$ Ir spots (fig. 5c). Graphene spots are visible and aligned with the $\operatorname{Ir}(111)$ spots (R0 rotation). A diffuse arc is also visible, due to multi-domain graphene. It is therefore possible to optimize the preparation by maximizing the intensity and sharpness of the graphene spots by varying the dosage and the temperature. Upon increasing the temperature to $800{ }^{\circ} \mathrm{C}$ while keeping the dosage at $34 \mathrm{~L}$ (fig. 5d), LEED features become sharper, and we distinguish the R0 spot, plus two other spots corresponding to graphene domains rotated $25^{\circ}$ and $35^{\circ}$ (further called R25 and R35). Some faint intensity from smaller rotational domains is still present. We settled in this way, the temperature to $800^{\circ} \mathrm{C}$, while increasing the dosage to 67.5 L (fig. 5e) and we reached our optimal preparation, the LEED of which is shown in detail in fig. 6. Four major graphene domains of rotations $0^{\circ}, 25^{\circ}, 30^{\circ}$ and $35^{\circ}$ are present in the sample(fig. 6a). Moreover, the one-dimensional
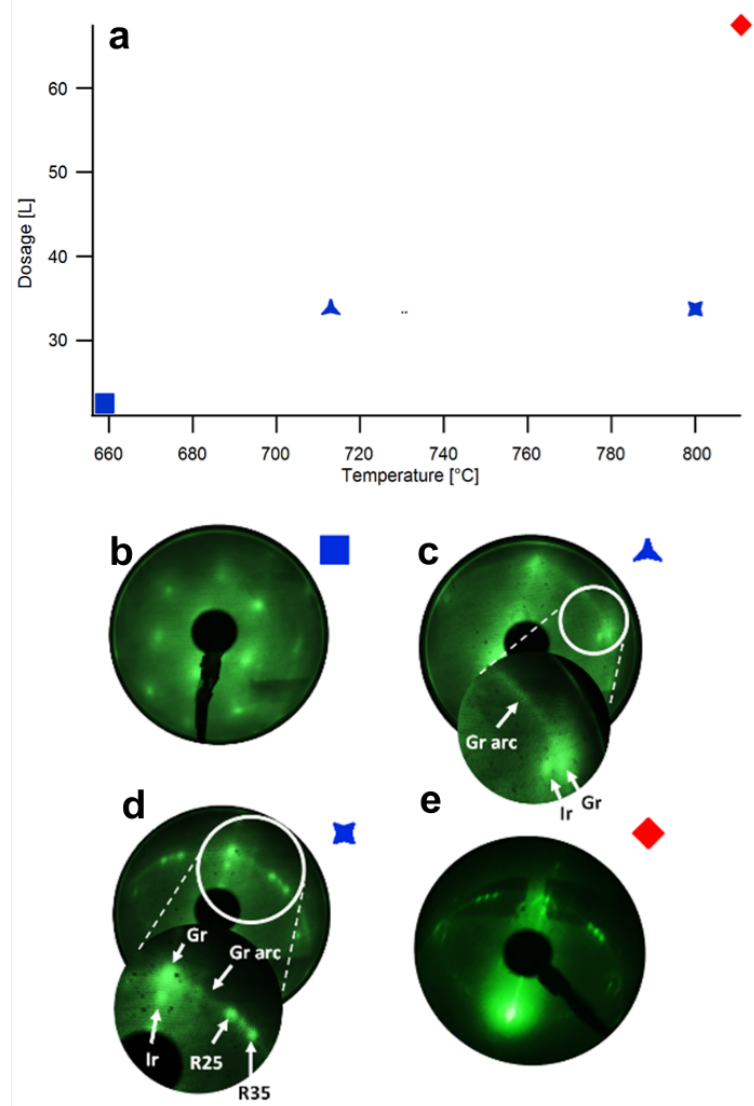

Figure 5. (a) Dosage vs. temperature diagram for different CVD preparations. The red rhombus shows the optimal preparation. (b)-(e) LEEDs corresponding to the different preparations in (a), as indicated by the square, triangle, star and rhombus. The beam energies were (b) $232 \mathrm{eV}$, (c-e) 66 eV. (b) (1x1) Ir spots and a diffuse background are present, but there is no graphene signal. (c) the $\mathrm{R} 0$ graphene spots are visible along with a diffuse arc representative of multi-domain graphene. (d) R0, R25 and R35 graphene spots are visible, in addition to a graphene arc. (e) LEED of the optimal preparation.

periodicity associated to the nanostructuration of the substrate is also observed, corresponding to a period of $\mathrm{L}=7.1 \pm 1.5 \mathrm{~nm}$. This periodicity is measured from the splitting of the $\operatorname{Ir}(111)$ spots. The STM image corresponding to these growth conditions is shown in fig. $6 \mathrm{~b}$. The surface is composed of terraces and step bunching areas (marked by the legends $\mathrm{T}$ and SB) giving rise to the superperiodicity obtained by LEED, while the terrace size is $3.5 \pm 0.5 \mathrm{~nm}$, roughly half of the periodicity obtained by LEED. Figure S3 in the supporting information shows the 3D repesentation of STM image where the periodicity can be seen clearly. The origin of this new 

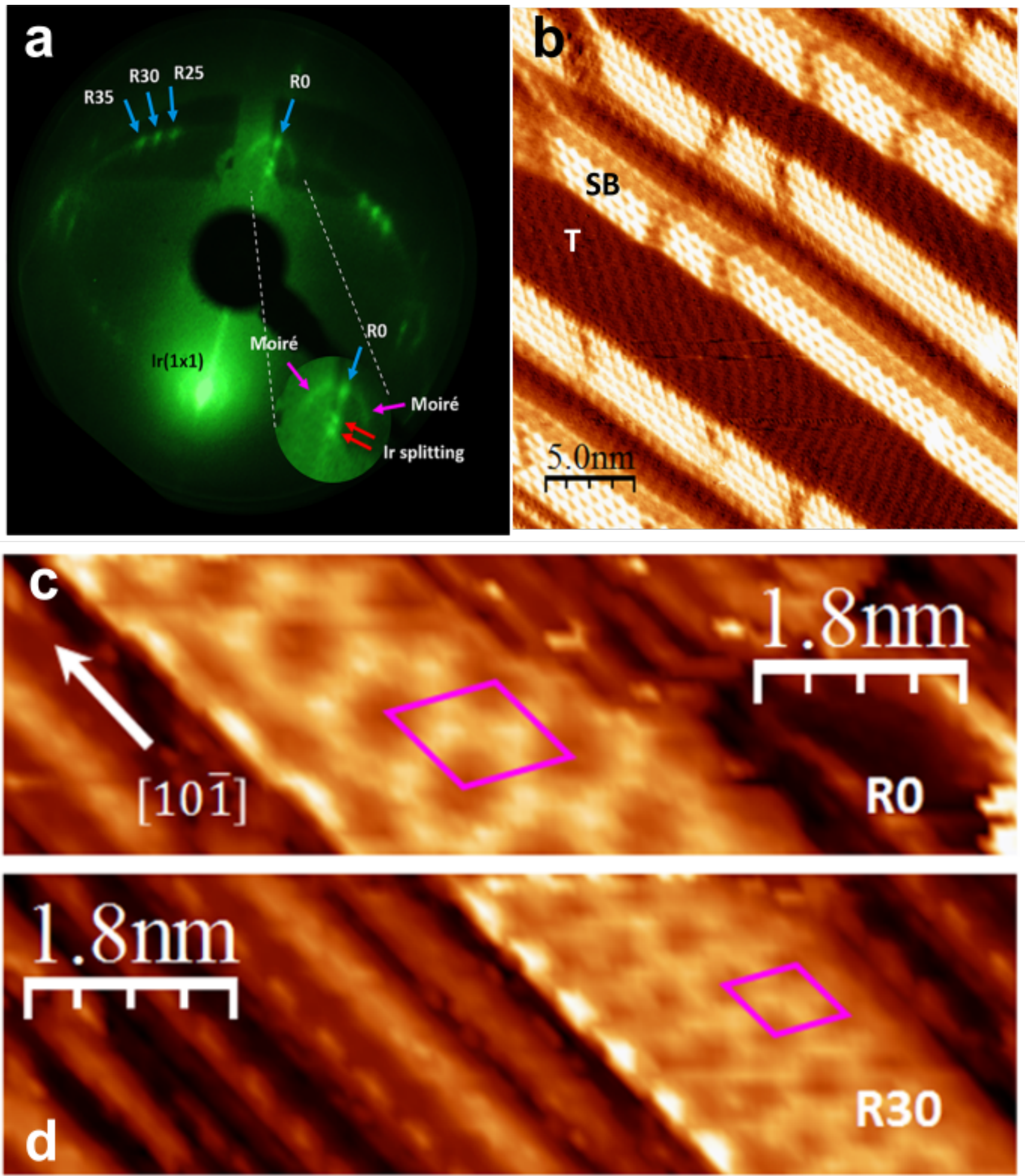

Figure 6. Optimal CVD sample $\left(810^{\circ} \mathrm{C}\right.$ and $\left.67.5 \mathrm{~L}\right)$. (a) LEED image for an electron beam energy of $63 \mathrm{eV}$. Spots associated to Ir, graphene and moiré periodicity of graphene on Ir are indicated by the arrows. The inset shows the Ir splitting due to a one-dimensional superperiodicity and the moiré spots. (b) STM image of the corresponding surface. Tunnelling conditions $\mathrm{V}_{\mathrm{T}}=0.9 \mathrm{~V}, \mathrm{IT}_{\mathrm{T}}=0.5 \mathrm{nA}$. Terrace $(\mathrm{T})$ and step bunching $(\mathrm{SB})$ areas are indicated. $(\mathrm{C})$ and $(\mathrm{d})$ STM images of the graphene $\mathrm{R} 0$ and $\mathrm{R} 30$ domains in $(\mathrm{a}) .\left(\mathrm{V}_{\mathrm{T}}=1 \mathrm{~V}, \mathrm{I}_{\mathrm{T}}=2 \mathrm{~A}\right)$. The pink rhombus indicates the unit cell of graphene moiré aligned with the substrate.

periodicity arises from the minimization of the surface energy into two stable orientations while preserving the initial optical surface that corresponded to a (332) surface. Moreover, STM shows that graphene completely covers the surface, as 
observed by the continuity of graphene across the terraces and the step bunch areas on Figure 6b, where graphene moiré is evident in the SB regions. Figure 6c and 6d show atomically resolved STM images of graphene R0 and R30 domains. The pink unit cell shows the graphene moire with the substrate.

\subsection{Electronic properties}

To understand the effect of the observed superperiodicity on the band structure of graphene, we performed detailed ARPES measurements.
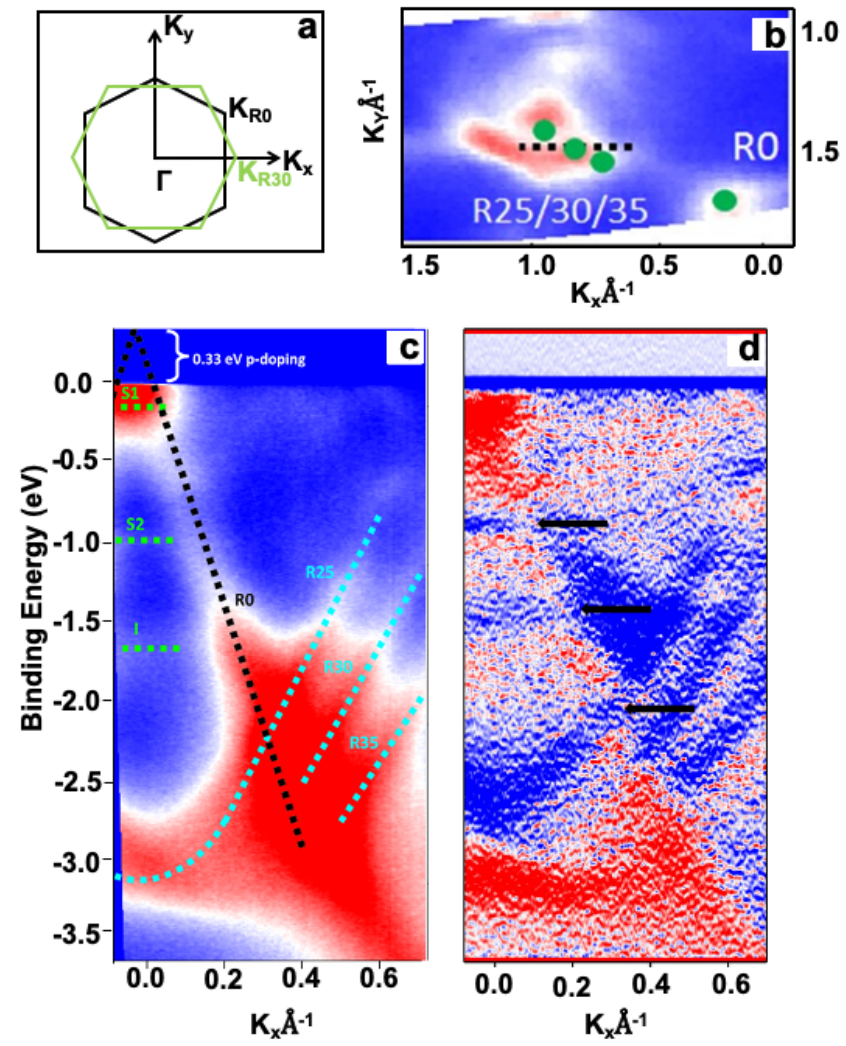

Figure 7. (a) Scheme of the first Brillouin zone of graphene indicating the high symmetry points of different rotational domains of graphene (b) ARPES constant energy cut at the Fermi level showing different rotational domains (R25, R30, R35) and R0. (c) E(k) map of $\mathrm{Gr} / \mathrm{Ir}(332)$ at the $\mathrm{K}$ point of the $\mathrm{R} 0$ rotation and $(\mathrm{d})$ its corresponding derivative. The green lines are a guide for the eye indicating the Ir surface states S1, S2 and I respectively. The cyan lines highlight the graphene cones of the different rotational domains (R25, R30, R35). The black line is the R0-domain band and shows a p-type doping of $330 \mathrm{meV}$. The black arrows in figure $7 \mathrm{~d}$ point to three band gaps in the Dirac cone.

Figure 7a shows the scheme of the first Brillouin zone with high symmetry points and (b) ARPES constant energy cut at the Fermi level showing different rotational domains (R25, $\mathrm{R} 30, \mathrm{R} 35$ ) and R0 from the terrace. (c) the dispersion of R0 graphene, using a photon energy of $32 \mathrm{eV}$ (d) and its corresponding second derivative. The black line in Figure 7c shows the linear dispersion of the $\pi$ band of the R0 domain. A doping of $330 \mathrm{meV}$ is appreciated on the experimental band structure in agreement with previous results[31]. The cyan lines correspond to the less intense R25, R30 and R35 domains. The green lines are identified as Ir states S1, S2 and I. S1 is closer to the Fermi level, and its intensity depends on the excitation energy[41]; in our case, it overlaps with the graphene band at the Fermi level. The Ir band at $-1 \mathrm{eV}$ is the $\mathrm{S} 2$ state[42]. Finally, the state at $1.6 \mathrm{eV}$ is the I band, whose spectral weight is also excitation energy-dependent. Along the graphene linear band, there are some places on which the spectral weight decreases. This can be better observed in the second-derivative of figure $7 \mathrm{c}$ as shown in figure $7 \mathrm{~d}$. Figure $7 \mathrm{~d}$ shows the decrease of spectral intensity of graphene pi band at three different locations marked by black arrows, characteristic of bandgap opening. It is interesting to note that the observed band gaps of $390 \pm 20 \mathrm{meV}$ with a separation in energy between gap is $0.60 \pm 0.06 \mathrm{eV}$ and in reciprocal space by a $\mathrm{G} / 2$ vector of $0.09 \pm 0.02 \AA^{-1}$, which corresponds to a periodicity of $3.5 \pm 0.9 \mathrm{~nm}$, which is in agreement with the characteristic width of the terraces and step bunching. There is therefore an effect of the nanostructuration on the electronic properties of graphene.

\section{Conclusions}

In summary, we have studied the growth procedure of graphene on $\operatorname{Ir}(332)$ substrate in order to tailor the electronic band structure by means of introducing a superperiodicity into the system. Two different methods have been explored: temperature-programmed growth (TPG) and chemical vapour deposition (CVD). TPG growth is performed by annealing the sample after ethylene exposure. Different temperatures and doses were examined for optimal growth conditions, which were monitored by LEED and STM. Despite the fact that the TPG technique produces graphene domains aligned with the underlying substrate and covering the (111) facets, it was difficult to obtain a long-range order surface periodicity. An alternative growth method was then studied, CVD growth was performed by annealing the substrate before ethylene exposure. A temperature versus dosage study was performed as in the case of TPG. In this case, a high level of ordering is reached, a factor essential for observing the band gap opening due to the superperiodicity by spatially averaging ARPES measurements. The periodicity could be varied by using different vicinal substrates and therefore tuning the energy location of the gaps, a promising way of tailoring graphene band structure. It would be also indeed interesting to supress 
the rotational domains by using other temperatures or dosages, for the simplicity of the analysis although this will not affect to the bandgap opening due to the superperiodicity.

\section{Experimental Methods}

Room-temperature (RT) and low-temperature (LT,77K) scanning tunnelling microscopy (STM) measurements were performed at the Surface Laboratory of SOLEIL and at the Institut Jean Lamour setup respectively. All STM images were treated using WSXM software[43]. Both setups are equipped with low energy electron diffraction (LEED). ARPES measurements were performed at CASSIOPEE beamline, which is also equipped with a LEED. The beamline spot size has 50 microns when using photon energies of $150 \mathrm{eV}$ and $36 \mathrm{eV}$. $\operatorname{Ir}(332)$ was prepared by sputtering and annealing cycles. The Ar+ sputtering was performed at RT, $1 \mathrm{keV}$ and with $2 \times 10^{-6} \mathrm{mbar}$ pressure during $10 \mathrm{~min}$. Annealing consisted in increasing the temperature to $650^{\circ} \mathrm{C}$ for $15 \mathrm{~min}$ and then slowly cooling down to RT at a rate of $20^{\circ} \mathrm{C} / \mathrm{min}$. LEED patterns were checked afterwards.

After the substrate preparation, graphene was prepared by temperature-programmed growth (TPG) or chemical vapor deposition technique (CVD). TPG consists of depositing hydrocarbon (ethylene) at RT onto the catalyst surface, followed by annealing above $600^{\circ} \mathrm{C}$ to promote the ethylene decomposition. While the hydrogen is evacuated through the UHV pumping system, the carbon remains at the metal surface. The thermal energy allows atoms to diffuse, nucleate, grow and/or merge islands of graphene. Since the carbon diffusion towards the Ir bulk is insignificant due to its low solubility[44], the annealing only promotes graphene formation. CVD consists of exposing a hot catalytic surface to a hydrocarbon gas (we chose again ethylene). Since the surface is already hot when the hydrocarbon lands at the surface, the dissociation of the molecule and graphene formation occur in a single step, contrary to the TPG technique. Depending on the cooling dynamics, graphene can form mono- or multi-rotational domains or even wrinkles[33,34,45,46]. After the hydrocarbon exposure on surface, the sample is cooled down to RT at $60^{\circ} \mathrm{C} / \mathrm{min}$. Both TPG and CVD are self-limiting processes that end once a graphene monolayer is formed because no catalytic sites from the substrate are then available to promote further graphene growth.

\section{Acknowledgements}

We acknowledge the financial support of the Agence Nationale de la Recherche (France) under contract CoRiGraph. We also thank Bertrand Kierren and Luc Moreau for helpful discussions and technical support.

\section{References}

[1] Zhou S Y, Gweon G-H, Fedorov A V, First P N, de Heer W A, Lee D-H, Guinea F, Castro Neto A H and Lanzara A 2007 Substrate-induced bandgap opening in epitaxial graphene. Nature materials 6 770-775

[2] Nevius M S, Conrad M, Wang F, Celis A, Nair M N, Tejeda A, Conrad E H 2015 Semiconducting graphene from highly ordered substrate interactions. Physical Review Letters 115136802 1-5

[3] Nair M N, Palacio I, Celis A, Zobelli A, Gloter A, Kubsky S, Turmaud J-P, Conrad M, Berger C, de Heer W.A, Conrad E H, Taleb-Ibrahimi A and Tejeda A 2017 Band Gap Opening Induced by the Structural Periodicity in Epitaxial Graphene Buffer Layer Nano Letters 174 2681-2689

[4] Conrad M, Wang F, Nevius M, Jinkins K, Celis A, Nair M N, Taleb-Ibrahim A, Tejeda A, Garreau Y, Vlad A, Coati A, Miceli P and Conrad E H 2017 Wide bandgap semiconductor from a hidden 2D incommensurate graphene phase Nano Letters 171 341-347

[5] Hicks J, Tejeda A, Taleb-Ibrahimi A, Nevius M S, Wang F, Shepperd K, Palmer J, Bertran F, Le Fèvre P, Kunc J, de Heer W A, Berger C and Conrad E H 2013 A wide-bandgap metal-semiconductor-metal nanostructure made entirely from graphene Nature Physics 9 49-54

[6] Palacio I, Celis A, Nair M N, Gloter A, Zobelli A, Sicot M, Malterre D, Nevius M S, de Heer W. A, Berger C, Conrad E H, Taleb-ibrahimi A and Tejeda A 2015 Atomic Structure of Epitaxial Graphene Sidewall Nanoribbons : Flat Graphene, Miniribbons, and the confinement gap Nano letters 151 182-189

[7] Celis A, Nair M N, Taleb-Ibrahimi A, Conrad E H, Berger C, de Heer W A and Tejeda A 2016 Graphene nanoribbons: fabrication, properties and devices Journal of Physics D: Applied Physics 49 143001

[8] Han M Y, Brant J C and Kim P 2010 Electron Transport in Disordered Graphene Nanoribbons Physical Review Letters 104056801 1-4

[9] Wong J-H, Wu B-R and Lin M-F 2012 Strain Effect on the Electronic Properties of Single Layer and Bilayer Graphene The Journal of Physical Chemistry C 116 8271-7

[10] Balog R, Jørgensen B, Nilsson L, Andersen M, Rienks E, Bianchi M, Fanetti M, Laegsgaard E, Baraldi A, Lizzit S, Sljivancanin Z, Besenbacher F, Hammer B, Pedersen T G, Hofmann P and Hornekaer L 2010 Bandgap opening in graphene induced by patterned hydrogen adsorption Nature Materials 9 315-319

[11] Zhang W, Lin C Te, Liu K K, Tite T, Su C Y, Chang C H, Lee Y H, Chu C W, Wei K H, Kuo J L and Li L J 2011 Opening an electrical band gap of bilayer graphene with molecular doping ACS Nano 5 
7517-24

[12] Castellanos-Gomez A, Wojtaszek M, Arramel, Tombros N and Van Wees B J 2012 Reversible hydrogenation and bandgap opening of graphene and graphite surfaces probed by scanning tunneling spectroscopy Small 8 1607-13

[13] Biel B, Triozon F, Blase X and Roche S 2009 Chemically induced mobility gaps in graphene nanoribbons: A route for upscaling device performances Nano Letters 9 2725-9

[14] Barbier M, Peeters F M, Vasilopoulos P and Pereira J M 2008 Dirac and Klein-Gordon particles in onedimensional periodic potentials Physical Review B 77115446 1-9

[15] Park C-H, Yang L, Son Y-W, Cohen M L and Louie S G 2008 New Generation of Massless Dirac Fermions in Graphene under External Periodic Potentials Physical Review Letters 101126804

[16] Tiwari R P and Stroud D 2009 Tunable band gap in graphene with a noncentrosymmetric superlattice potential Physical Review B 79 1-5

[17] Barbier M, Vasilopoulos P and Peeters F M 2010 Extra Dirac points in the energy spectrum for superlattices on single-layer graphene Physical Review B 81075438 1-7

[18] Wang L G and Zhu S Y 2010 Electronic band gaps and transport properties in graphene superlattices with one-dimensional periodic potentials of square barriers Physical Review B 81205444 1-9

[19] Ramezani Masir M, Vasilopoulos P, Matulis A and Peeters F M 2008 Direction-dependent tunnelling through nanostructured magnetic barriers in graphene Physical Review B 77235443 1-11

[20] Dell'Anna L and De Martino A 2009 Multiple magnetic barriers in graphene Physical Review B 79 045420 (1-9)

[21] Meyer J C, Girit C O, Crommie M F and Zettl A 2008 Hydrocarbon lithography on graphene membranes Applied Physics Letters 92123110

[22] Marchini S, Günther S and Wintterlin J 2007 Scanning tunnelling microscopy of graphene on Ru(0001) Physical Review B 76075429 1-9

[23] Vázquez De Parga A L, Calleja F, Borca B, Passeggi M C G, Hinarejos J J, Guinea F and Miranda R 2008 Periodically rippled graphene: Growth and spatially resolved electronic structure Physical Review Letters 100 0568071-4

[24] Pletikosić I, Kralj M, Pervan P, Brako R, Coraux J, N'Diaye A T, Busse C and Michely T 2009 Dirac cones and minigaps for graphene on $\operatorname{Ir}(111)$ Physical Review Letters 102 1-4

[25] Celis A, Nair M N, Sicot M, Nicolas F, Kubsky S, Malterre D and Tejeda A 2018 Superlattice-induced minigaps in graphene band structure due to underlying one-dimensional nanostructuration Physical Review B 97195410 1-6

[26] Park C H, Yang L, Son Y W, Cohen M L and Louie S G 2008 Anisotropic behaviours of massless Dirac fermions in graphene under periodic potentials0 Nature Physics 4 213-7

[27] Ho J H, Chiu Y H, Tsai S J and Lin M F 2009 Semimetallic graphene in a modulated electric potential Physical Review B 79 1-7

[28] Nakatsuji K, Yoshimura T, Komori F, Morita K and Tanaka S 2012 Uniaxial deformation of graphene Dirac cone on a vicinal SiC substrate Physical Review B 85 1-6

[29] Bai K K, Zhou Y, Zheng H, Meng L, Peng H, Liu Z, Nie J C and He L 2014 Creating one-dimensional nanoscale periodic ripples in a continuous mosaic graphene monolayer Physical Review Letters 113 15

[30] Lin C, Huang X, Ke F, Jin C, Tong N, Yin X, Gan L, Guo X, Zhao R, Yang W, Wang E and Hu Z 2014 Quasi-one-dimensional graphene superlattices formed on high-index surfaces Physical Review B 89 $1-5$

[31] Šrut Rakić I, Kralj M, Jolie W, Lazić P, Sun W, Avila J, Asensio M C, Craes F, Mikšić Trontl V, Busse C and Pervan P 2016 Step-induced faceting and related electronic effects for graphene on $\operatorname{Ir}(332)$ Carbon 110 267-77

[32] Šrut I, Mikšić Trontl V, Pervan P and Kralj M 2013 Temperature dependence of graphene growth on a stepped iridium surface Carbon 56 193-200

[33] Hattab H, N'Diaye A T, Wall D, Jnawali G, Coraux J, Busse C, Van Gastel R, Poelsema B, Michely T, Meyer Zu Heringdorf F J and Horn-Von Hoegen $\mathrm{M}$ 2011 Growth temperature dependent graphene alignment on $\operatorname{Ir}(111)$ Applied Physics Letters 98 141903

[34] Kralj M, Pletikosić I, Petrović M, Pervan P, Milun M, N'Diaye A T, Busse C, Michely T, Fujii J and Vobornik I 2011 Graphene on $\operatorname{Ir}(111)$ characterized by angle-resolved photoemission Physical Review $B$ 84075427

[35] N'Diaye A T, Coraux J, Plasa T N, Busse C and Michely T 2008 Structure of epitaxial graphene on $\operatorname{Ir}(111)$ New Journal of Physics 10043033

[36] Coraux J, N'Diaye A T, Engler M, Busse C, Wall D, Buckanie N, Meyer Zu Heringdorf F J, Van Gastel R, Poelsema B and Michely T 2009 Growth of graphene on $\operatorname{Ir}(111)$ New Journal of Physics 11 023006

[37] Phark S H, Borme J, Vanegas A L, Corbetta M, Sander D and Kirschner J 2012 Atomic structure and spectroscopy of graphene edges on $\operatorname{Ir}(111)$ Physical Review B - 86045442 1-4

[38] Günther S, Dänhardt S, Wang B, Bocquet M L, Schmitt S and Wintterlin J 2011 Single terrace growth of graphene on a metal surface Nano Letters $115,1895-1900$

[39] Hupalo M, Conrad E H and Tringides M C 2009 Growth mechanism for epitaxial graphene on vicinal 6H-SiC (0001) surfaces: A scanning tunnelling microscopy study Physical Review B - 80 041401(R) 
(1-5)

[40] Sicot M, Fagot-Revurat Y, Kierren B, Vasseur G and Malterre D 2014 Copper intercalation at the interface of graphene and $\operatorname{Ir}(111)$ studied by scanning tunnelling microscopy Applied Physics Letters 105191603

[41] Starodub E, Bostwick A, Moreschini L, Nie S, Gabaly F El, McCarty K F and Rotenberg E 2011 Inplane orientation effects on the electronic structure, stability, and Raman scattering of monolayer graphene on $\operatorname{Ir}(111)$ Physical Review B 83125428

[42] Pletikosić I, Kralj M, Okević D, Brako R, Lazić P and Pervan P 2010 Photoemission and density functional theory study of $\operatorname{Ir}(111)$; Energy band gap mapping Journal of Physics Condensed Matter 22 135006

[43] Horcas I, Fernández R, Gómez-Rodríguez J M, Colchero J, Gómez-Herrero J and Baro A M 2007 WSXM: A software for scanning probe microscopy and a tool for nanotechnology Review of Scientific Instruments 78013705

[44] Arnoult W J and McLellan R B 1972 The solubility of carbon in rhodium ruthenium, iridium and rhenium Scripta Metallurgica 10 1013-1018

[45] Loginova E, Nie S, Thürmer K, Bartelt N C and McCarty K F 2009 Defects of graphene on $\operatorname{Ir}(111)$ : Rotational domains and ridges Physical Review B 80 $0854301-8$

[46] Coraux J, N'Diaye A T, Busse C and Michely T 2008 Structural coherency of graphene on $\operatorname{Ir}(111)$ Nano Letters 8 565-70 